\title{
MICROCELEBRIDADES entre meios digitais e massivos
}

\begin{abstract}
Adriana Braga ${ }^{2}$
Resumo: Este artigo busca discutir alguns aspectos do fenômeno a que denominei "microcelebridades" (Braga, 2008), participantes que se celebrizaram no âmbito das redes sociais na Internet. A dispersão do polo da produção midiática promovida pela Comunicação Mediada por Computador (CMC) perece radicalizar a ideia de "recepção ativa." As microcelebridades são um fenômeno emergente neste universo, e sua crescente popularidade não raras vezes resulta em atuações nos meios de comunicação de massa $(M C M)$. Este artigo busca explorar justamente este ângulo do fenômeno, a interação entre microcelebridades e meios de comunicação de massa, particularmente a televisão, a partir de dois casos emblemáticos: a transposição do conteúdo de um blog para o formato de seriado de $t v$, e a participação de uma twiteira no programa Big Brother Brasil 10, da Rede Globo.
\end{abstract}

Palavras-chave: Redes Sociais. Meios de Comunicação de Massa. Microcelebridade.

\begin{abstract}
This paper regards the so-called "microcelebrities"(Braga, 2008), participants that acquired celebrity in social networks on the Internet. The dispersion of media production allowed by Computer-Mediated Communication (CMC) practices seems to bring the idea of "active audiences" to a new standard. Microcelebrities are an emerging phenomenon in this universe, and their growing popularity result very often in participation on the traditional mass-media. This paper explores exactly this aspect of the phenomenon, the interaction between microcelebrities and the mass-media, specially television, analysing two emblematic situations: the the adaptation of the contents of a blog to a sitcom, and the participation of a "twitter-celebrity" on the "Big Brother Brasil 10" from Globo Network.
\end{abstract}

Key-words: Social Media. Mass Media Communication. Microcelebrities.

Em fevereiro de 2010, uma noite insuspeitada de terça-feira registrou um fenômeno de audiência midiática: no terceiro "paredão" do programa Big Brother Brasil 10, foram contabilizados 32 milhões de votos, dos quais $78 \%$ rejeitando uma das participantes, a twiteira Tessália, de 22 anos, em um total estimado de 25 milhões de votos. A inusitada participação da audiência em uma etapa tão inicial do programa, somada à repercussão do caso na imprensa e às manifestações de repúdio à jogadora nos espaços de comentários dos principais portais de notícias revela um fenômeno midiático que demanda interpretação.

\footnotetext{
${ }^{1}$ Uma versão preliminar deste artigo foi apresentada durante o XIX Encontro Anual da Compós. Rio de Janeiro, junho, 2010.

${ }^{2}$ Professora do Programa de Pós-Graduação em Comunicação da PUC/RJ. Email: adrianabraga1 @ yahoo.com.br.
} 
Tessália, antes de entrar no programa de tv que confina os participantes em uma casa monitorada por dezenas de câmeras, era uma célebre twiteira, com dezenas de milhares de seguidores/as, conhecida como "Tess."

Quatro anos antes, em meados de 2006, duas blogueiras lançaram um livro com os textos publicados no blog chamado Mothern, dedicado à temática da maternidade moderna. $\mathrm{O}$ livro, assim como o blog, foi um sucesso editorial, e as duas foram contatadas por uma produtora de tv para adaptar seus textos ao primeiro seriado de tv por assinatura no Brasil, para veiculação no canal GNT. Concedida a autorização, a participação das blogueiras na concepção do seriado ficou limitada à "consultoria," sem poder de decisão sobre elenco, roteiro ou argumento. A notícia de que o blog de sucesso seria um programa de tv levou as autoras às telas de várias emissoras, na condição de entrevistadas em programas como os de Marília Gabriela e Hebe Camargo.

Os dois casos são emblemáticos de um mesmo fenômeno: as complexidades envolvidas na interação entre meios digitais e massivos, particularmente no que tange à relação de poder entre produtores/as de conteúdos de cada um dos meios. A CMC constitui-se em um aspecto interessante do universo dos usos midiáticos, uma vez que as interações mediadas por computador e suas intensas trocas comunicativas entre múltiplos enunciadores parecem radicalizar a ideia de "recepção ativa." Redes de comentários em portais de notícias, visitas recíprocas a blogs e twitters, contas no Youtube, perfis em redes sociais etc., são alguns exemplos dessas modalidades de participação ativa dos sujeitos, que já não são mais adequadamente descritos pelos termos "audiência" ou "recepção." A facilidade de publicação e os ínfimos custos de produção possibilitaram a emergência de uma multitude de novos enunciadores nos meios digitais. Não obstante, continuam a haver hierarquizações simbólicas entre esses enunciadores. Por serem múltiplos, não significa que sejam iguais em poder. Alguns deles/as se destacam em seu circuito interacional próprio, ganham seguidores/as e fãs em números notáveis, e suas opiniões são mais valorizadas do que as dos/as demais participantes. Chamei a esse fenômeno de celebrização no ambiente restrito das redes sociais de "microcelebridade"3 (BRAGA, 2008).

As microcelebridades são um fenômeno emergente neste universo, e sua crescente popularidade não raras vezes resulta em atuações nos meios de comunicação de massa, seja pela adaptação para livros dos conteúdos on-line, como colunistas em jornais e revistas, como

\footnotetext{
${ }^{3}$ Há nas Ciências Sociais de língua inglesa uma vertente de estudos denominada Celebrity Studies, com vasta literatura e até mesmo um periódico científico especializado (ver HOLMES\&REDMOND, 2010; DYER, 1986; MARSHALL, 2006). Entretanto, não pretendo me alongar nesse tema, que se dedica à caracterização de um fenômeno da mídia massiva, enquanto neste estudo analiso um fenômeno específico das redes sociais.
} 
entrevistados/as em programas de rádio e televisão. Este artigo busca explorar justamente este ângulo do fenômeno, a interação entre microcelebridades e meios de comunicação de massa. O que acontece quando as lógicas da produção midiática on-line (baixo custo, acesso livre, multiplicidade de produtores/as de conteúdo, celebrização por redes de sociabilidade, baixo grau de legitimidade simbólica) se encontram com as lógicas da produção midiática de massa (alto custo, poucos produtores, acesso restrito, celebrização por exposição massiva, alto grau de legitimidade simbólica)?

\section{Personas digitais}

Os ambientes de Internet são largamente utilizados por pessoas não especializadas como meio de comunicação e expressão individual ou coletiva, fornecendo espaço social para apresentações do self, veiculação de representações de identidade e de individualidade, em uma dinâmica de "gerenciamento da impressão" (impression management), análoga à denominação de Goffman (1998). Segundo esse autor, uma pessoa, ao se apresentar, pode agir de várias maneiras em uma antecipação ao que os outros esperam dela. O processo de apresentação de si nos contextos digitais se dá de diversas maneiras, utilizando recursos de texto, áudio e imagem.

Atualmente, é possível observar instâncias nas quais os níveis de afeto e emoção desenvolvidos nas relações estabelecidas via Internet podem ser similares ou mesmo ultrapassar aqueles estabelecidos em relações face a face ou mediadas por outros suportes técnicos. Alguns/as autores/as (WALTHER, 1996; BARNES, 2003) denominam este fenômeno comunicação hiperpessoal, casos em que há uma preferência pela $\mathrm{CMC}$, por permitir uma apresentação do self mais seletiva, maior tempo de reflexão, apuração, edição e seleção das informações a serem transmitidas à recepção.

No estudo das práticas de uso e consumo de mídia, um ponto importante para observação é a dinâmica da apresentação do self de cada participante na situação de interação, uma vez que essas práticas são mediadas por definições - negociadas no interior de cada grupo - acerca do que é 'certo,' 'bom' ou 'moral,' conforme o sistema de valores do contexto interacional em questão.

A noção de 'definição da situação' (THOMAS, 1926) é central para se compreender o modo como as pessoas orientam suas ações cotidianamente. ${ }^{4}$ Uma definição equivocada pode causar constrangimentos e um desfecho desfavorável para a situação. Definir corretamente a

\footnotetext{
${ }^{4}$ Sobre a noção de 'definição da situação' aplicada a objetos comunicacionais, ver Braga e Gastaldo, 2009.
} 
situação garante o entendimento do que está acontecendo, visando alinhar-se adequadamente às diferentes situações que se apresentam.

Entretanto, este não é um processo individual, interno ao sujeito. As diferentes maneiras de definir uma situação estão permeadas por relações de poder. Quem tem o poder de definir mais legitimamente o que está acontecendo ou, numa dimensão mais particular ainda, o que alguém ou alguma coisa “é." Howard Becker (2004) traz um exemplo elucidativo:

Consideremos o caso da maconha. As pessoas que a usam têm uma linguagem para se referir a ela. Elas falam em 'viajar,' e têm muitos sinônimos para maconha, referindo-se a ela, por exemplo, como 'marofa.' (...) Outras pessoas, cujos mundos também incluem a maconha - médicos, advogados, policiais - terão outras palavras para as mesmas coisas, talvez falando de 'adição,' 'cannabis,' e 'traficantes.' (...) O modo pelo qual as coisas são chamadas quase sempre reflete relações de poder. As pessoas no poder chamam as coisas do que quiserem, e as outras têm que se ajustar a isso, talvez usando suas próprias palavras em privado, mas aceitando aquilo de que não podem escapar (BECKER, 2004, p. 102).

A definição de uma situação implica em relações de poder na medida em que algumas definições são mais legítimas do que outras, e essa legitimidade é resultante de quem tem o poder de propor e sustentar essa definição.

\section{A noção de microcelebridade}

A introdução da Internet permitiu, entre outras coisas, certa relativização do monopólio de produção de conteúdos midiáticos, vigente desde o surgimento dos meios eletrônicos. Esta constatação é reiteradamente valorizada e comemorada na literatura da área, bem como no contexto da indústria e comércio desses equipamentos. Entretanto, em termos de impacto de veiculação nenhum conteúdo de Internet pode ainda rivalizar com um programa de televisão. Porém, o fato de não requerer do/a produtor/a um investimento expressivo, e de não necessitar enfrentar as chamadas 'barreiras à entrada' (BRITTOS, 2005) presentes no estruturado mercado de televisão, os ambientes digitais têm sido empregados pelos mais diversos perfis de produtores/as, colocando no campo discursivo midiático um número expressivo de novos sujeitos enunciadores. Essa consequência tem permitido a emergência de fenômenos como o analisado neste estudo. Sem o descomprometimento que só é possível ter quando nenhum capital foi investido além de tempo de produção e divulgação, 
dificilmente subjetividades como as microcelebridades existiriam, uma vez que sua construção necessitaria de, no mínimo, um considerável investimento financeiro em produção, diagramação, composição, impressão e distribuição, em forma impressa. Em forma eletrônica, os investimentos seriam ainda mais elevados.

Assim, a introdução da Internet, suscitando a emergência de inúmeros novos atores no campo discursivo das mídias, provocou, entre outras alterações, uma dispersão do monopólio da produção e veiculação midiática de conteúdos, diluindo, pela quantidade de pequenos novos sujeitos enunciadores em condição de disponibilizar conteúdos em larga escala, o chamado "poder da mídia," descentralizando, de certa maneira, o oligopólio da enunciação midiática. Assim, essa tecnologia configura, além de uma multiplicidade de oferta enunciativa, ambientes de interação social, que são apropriados por grupos diversos, que, constrangidos pelos limites e possibilidades do meio, estabelecem diferentes formas de sociação.

A interatividade e o recurso de utilização da hipertextualidade característicos desses ambientes proporcionam a formação de uma listagem de indicação de links constituída a partir dos interesses temáticos do grupo, o que gera uma rede de interações comunicativas e circulação de saberes específicos por essa via. Desta forma, ampliou-se a oferta de sentidos, as representações no campo das mídias, trazendo novas expressões ao já intrincado e complexo campo simbólico das representações midiáticas.

Amplia-se, nesse movimento, o espaço de acolhimento e visibilidade da expressão individual ou interesses de grupos específicos. Entretanto, é importante ressaltar que este mesmo movimento, que promove a "democratização" deste ambiente, entendido como espaço público, tem como para-efeito a banalização e desconfiança com relação a grande parte dos conteúdos publicados. Páginas na Web são criadas por uma miríade de indivíduos e organizações, tornando indispensável uma avaliação das informações veiculadas quanto à exatidão, autoridade, objetividade, segurança e atualidade por parte de quem utiliza. Na medida em que "qualquer pessoa" pode produzir e veicular informação, esse conteúdo passa a ser duvidoso. Não é raro observar em várias instâncias da Internet a utilização deste espaço como uma possível via de acesso às mídias tradicionais, que possuem a legitimidade pretendida pelos/as autores/as.

As redes sociais parecem facultar o surgimento de um tipo de subjetividade a que tenho chamado microcelebridade. São pessoas comuns, de idades e profissões variadas, que se aventuram a produzir conteúdos no âmbito da chamada Web 2.0, estimuladas pelas 
facilidades que a ferramenta apresenta. Entretanto, algumas delas se destacam, ganhando enorme projeção pela legitimidade que conquistam em seus círculos.

Em várias ocasiões, ocorrem encontros presenciais dessas personas com seus fãs, como em eventos nos quais são convidadas a participar como palestrantes ou reuniões face a face agendadas pelo grupo no ambiente digital. Nestes encontros, observa-se um comportamento por parte dos fãs dessas microcelebridades similares àqueles observados com relação às celebridades dos meios massivos: pedidos de autógrafo, oferta de presentes e registros em fotografias da microcelebridade em companhia do/a fã.

A legitimação de conteúdos e autores/as dos ambientes digitais parece ter seus processos específicos, entre os quais destaco a legitimação pelo público, através do número de visitantes a acessar e comentar os conteúdos e a legitimação pelos pares, através de onde e quanto o perfil é citado e linkado em outros espaços semelhantes. Quanto mais prestigiosos os espaços que fizeram a citação, mais legitimado o personagem em processo de legitimação estará (BRAGA, 2009). O fato é que, uma vez legitimados neste domínio, alguns/as autores/as ganham tanta projeção no âmbito da Internet que passam a chamar a atenção dos meios de comunicação de massa. A aparição desses personagens nas mídias tradicionais é comentada amplamente nos contextos digitais, na maior parte das vezes em tom comemorativo, uma espécie de confirmação de seu valor já demonstrado na Internet, outras vezes, entretanto, em tom crítico, pela rendição ao fascínio que os meios massivos exercem. A essas personas, elevadas à condição de celebridades no seu micro âmbito de atuação, denominei "microcelebridades."

Trata-se de processos midiáticos altamente seletivos em termos da audiência, na medida em que esses ambientes de mídia conquistam um público específico correspondente à temática tratada. Sendo assim, o prefixo 'micro' se justifica por se tratar da produção de fenômenos midiáticos análogos àqueles observados nos MCM, nos quais o personagem se celebriza no seu ambiente, entretanto, em pequena escala. Ou seja, mesmo que se possa argumentar que a Internet tenha um alcance planetário, elementos de ordem interacional, como comunicação a partir de circuitos interativos e idioma, limitam o alcance da celebrização dessas personas a um âmbito restrito, micro. Esses processos operam como elemento importante na formação de circuitos interacionais, na medida em que estabelecem uma hierarquização simbólica, tácita nas redes sociais e seus/suas autores/as, decisiva na configuração desta dinâmica comunicacional. 


\section{Entre meios digitais e massivos}

Para Goffman, a maior parte da interação social cotidiana é possibilitada pelo engajamento comum e voluntário dos/as participantes no que ele chama de "consenso operacional" (GOFFMAN, 1998), uma espécie de concordância superficial, onde cada participante abstrai suas posições pessoais em prol de uma definição da situação compartilhada por todos/as.

Goffman considera que há duas espécies de expressividade do indivíduo, atividades bastante diferentes, mas igualmente significativas: a expressão transmitida, ligada à linguagem verbal e à intencionalidade, e a expressão emitida, que inclui os gestos, olhares, suores, sorrisos ou expressões faciais, permitindo inferências alheias nem sempre controladas pelo indivíduo. A teorização de Goffman sobre a ordem da interação face a face parece se aplicar muito bem ao objeto sob investigação, mesmo que os dados apontem também diferenças importantes. No caso dos ambientes digitais, há menos elementos de emissão de expressão, somente aqueles veiculáveis por forma verbal, havendo uma preponderância da informação deliberadamente transmitida. Isso traz consequências ao tipo de interação que se estabelece. Relativamente livres da expressividade via emissão, os sujeitos encontram menos obstáculos - ou obstáculos de outra ordem - em tentar manejar a impressão causada através de tentativas de controle com relação à informação fornecida.

Tais possibilidades de controle da informação são limitadíssimas quando uma microcelebridade recebe um convite para participar de um programa de televisão, por exemplo. A pauta, o tempo disponível para falar, a luz, o enquadramento da câmera, o horário e local da gravação etc., não são controlados pelo/a convidado/a, e mesmo suas palavras são ou podem ser editadas, de modo a fundamentar argumentos ou posições da emissora, com os quais muitas vezes ele/ela não concorda. ${ }^{5}$ Este ponto pode ser observado, por exemplo, na fala de um ex-BBB, considerado um vilão da casa na época, entrevistado recentemente por ocasião da performance desastrosa de Tessália, objeto desse estudo:

Esse lance de ser a grande vilã, acho que não existe! (...) Falam que eu fui um grande vilão, beleza?! Mas posso ir contra isso, porque foi a imagem que a Globo passou. E a única coisa positiva é que mesmo sendo vilão sou

\footnotetext{
${ }^{5}$ Aliás, esse problema atinge a todos/as os que concedem entrevistas ou participam de programas de rádio e tv, não somente microcelebridades. Devido a esses constrangimentos, Pierre Bourdieu (1998), por exemplo, somente permitiu que sua imagem fosse televisionada se ele dispusesse de uma hora para falar sozinho, na sala de conferências do College de France, sem pauta predefinida, sem cortes, edições ou intervalos comerciais, condições de produção dificilmente negociáveis por outras pessoas.
} 
lembrado até hoje (Alberto Cowboy - BBB7, em entrevista à Revista Tititi, 05/02/2010, p. 21).

\section{Notas sobre método}

Serão analisados a seguir dois eventos de interação entre microcelebridades e meios de comunicação de massa: a transposição do blog Mothern para o formato sitcom, e a trajetória da twiteira Tessália no reality show Big Brother Brasil 10. Os dados foram obtidos de diversas fontes. Foram coletados trechos de textos publicados em blogs, twitter e comentários deixados por leitores/as em portais de notícias na Internet, além de jornais e revistas de diversos âmbitos de circulação, particularmente na sequência da eliminação de Tess. As imagens de televisão foram coletadas no website Youtube. Foi dada particular atenção às figuras de Tess e do apresentador Pedro Bial, "voz oficial" da emissora no episódio. Além disso, no caso do blog Mothern, foram também realizadas entrevistas presenciais, por e-mail e telefone com as blogueiras e frequentadoras daquele circuito de interação.

A análise dos dados segue uma linha de análise do discurso ${ }^{6}$, em que os elementos textuais dessas diversas fontes são articulados em uma cadeia significante, de modo a permitir uma interpretação conjunta dos dois eventos.

\section{a) $O$ caso Mothern}

A criação do blog Mothern surgiu a partir de uma iniciativa entre duas publicitárias, colegas de trabalho, que identificavam a ausência de uma representação midiática materna com a qual elas se identificassem. No sentido de dispersão e divulgação do blog, várias ações foram feitas pela dupla, como envio de e-mails para pessoas conhecidas e editores/as de publicações afinadas com o tema, bem como visitas em blogs com os quais desejavam aproximação. Nestas ações, havia um movimento na direção da legitimação de seus conteúdos através do reconhecimento de pares e das mídias tradicionais, e a tentativa de obter resultados que ultrapassassem as fronteiras digitais. Com o resultado bem-sucedido dessa ação inicial, manifesto no elevado número de acessos, comentários e referências ao blog, passou a fazer parte do objetivo das blogueiras a criação de uma "teoria" materna que pudesse "catequizar" as mulheres interessadas, nas palavras de uma delas.

\footnotetext{
${ }^{6}$ Sobre aspectos teóricos e metodológicos da Análise do Discurso, ver Charaudeau (1984) e Maingueneau (1998).
} 
No caso desse grupo, em um primeiro momento, o território recém descoberto da blogosfera foi ocupado pelas blogueiras, usuárias leigas de computador, que, entre tentativas e erros, experimentavam a novidade. As mensagens enviadas pelas sócias do recém-criado blog, que informavam da sua existência e convidavam para uma visita foram endereçadas para grandes listas de e-mail pessoal. Entretanto, a blogosfera é um sistema que se autoalimenta: os/as "desblogados" visitam vez ou outra, enquanto aqueles/as que também mantêm seus próprios blogs na rede visitam todos os dias, configurando grupos de frequentadores/as. O primeiro grupo abrigado no blog compareceu principalmente a partir das visitas feitas previamente pelas blogueiras em outros blogs que admiravam, em uma lógica de retribuição. Ao descobrirem as leis que regem a blogosfera - "a linkania, os comments, a circulação e capilaridade de meio," (trecho de entrevista) começaram a comentar nos blogs de afinidade e a receber visitas de interesse. Assim, há uma grande identificação entre o perfil desse primeiro grupo e as próprias blogueiras. Nas palavras de uma delas, "essa primeira geração de leitoras era muito legal e bem 'mothern' mesmo: gente parecidíssima com a gente." Este primeiro grupo era composto por outras blogueiras, usuárias acostumadas à dinâmica específica desses ambientes. Essa atitude se reflete no teor ousado das temáticas tratadas, nas posições pessoais explicitadas durante momentos de tensão, de modo geral próximas de um ideal libertário e contestador dos costumes.

Em um segundo momento, quando o blog começou a ganhar alguma projeção em mídias de massa, como jornais e revistas, outras participantes se apresentaram, vindas principalmente por indicação de revistas especializadas, a consolidar um grupo que, integrando-se ao primeiro, apresentava uma disposição para discutir questões de gênero e abertas a mudanças. Este grupo ampliado se dispersou do blog com a criação de uma lista de discussão privada, que não possibilita meios de localização por sistemas de busca, e oferece a privacidade que esse grupo buscava para discutir assuntos-tabu ou polêmicos, sem a visibilidade pública e suas consequências.

O próximo grupo a se estabelecer no blog foi atraído para aquele ambiente através da veiculação de reportagens em produtos de mídia de massa mais ampla, na medida em que o blog passou a ser pauta frequente desses veículos quando o assunto era "informática + comportamento," ou ainda, "maternidade nos dias de hoje." Mesmo com a pouca atualização do blog nesse período, este grupo instalou ali sua conversação e manteve o funcionamento do espaço. A falta de afinidade das blogueiras com este grupo e sua consequente ausência no ambiente do blog criou uma relação entre elas parecida com aquela estabelecida entre fãs e ídolos. Nas temáticas tratadas, desapareceram os conteúdos polêmicos, parecendo haver uma 
atitude geral mais conservadora, com preferência por assuntos acerca da maternidade propriamente dita.

Assim, a Internet entra como mais um recurso tecnológico participante de uma complexa relação com outros suportes. A Internet parece oferecer meios de democratização dos processos de produção e veiculação de conteúdos discursivos para seus/suas usuários/as, trazendo à cena uma inumerável diversidade de novos/as enunciadores/as e representações sociais das mais diversas ordens - do fascismo ao anarquismo - que se beneficiam da relativa ausência de regulamentação e custo de produção dos conteúdos a que estão sujeitos os MCM. Entretanto, na medida em que os conteúdos veiculados através da CMC não têm a credibilidade e legitimidade desejada por seus/suas autores/as, estes/as buscam frequentemente na rede mundial uma via de acesso às mídias tradicionais, nas quais os altos números envolvidos na produção são proporcionais aos números da audiência, que se materializa na maioria das vezes na forma de lucro.

Mas, muitas vezes, paga-se um preço nesse deslocamento. É necessário fazer concessões para habitar o espaço dos MCM. Na medida em que a transição de um meio a outro foi feita, no caso do Mothern, parece ter havido uma diluição no teor crítico das representações propostas: de provocadoras e questionadoras da ordem social no contexto do blog, para outras mais conservadoras e próximas dos estereótipos tradicionais, no contexto da televisão.

O contrato das blogueiras com a produtora que realizou a adaptação dos textos do blog para o formato audiovisual deixava bem clara a participação das autoras. Em troca de um valor em dinheiro estipulado previamente, as blogueiras cederiam totalmente os direitos autorais sobre o conteúdo do blog. A produtora convidou informalmente as autoras para manter contato com o roteirista através de mensageiro instantâneo para que elas pudessem auxiliá-lo na construção do roteiro para o sitcom, desde que tais sugestões fossem usadas apenas na medida do interesse da produtora. $\mathrm{Na}$ criação das personagens principais, quatro mães jovens e modernas, por exemplo, as blogueiras sugeriram a presença de mulheres negras, homossexuais, alternativas, acima do peso ou de baixa renda. Segundo elas, esses perfis representariam melhor o grupo de participantes do blog. Entretanto, foram efetivamente usadas quatro mulheres de perfil idêntico: brancas, magras, jovens e ricas. Para negar a demanda, foi alegado que isso garantiria a veiculação do programa no canal da Globosat, como de fato aconteceu. A produtora, que já havia feito outros produtos para a emissora, gravou um piloto do programa com os "padrões Globo" já introjetados, apostando na sua aceitação e inclusão na grade de programação do GNT, além de grandes patrocinadores. Vale 
ressaltar que as escolhas da produtora garantiram o interesse da poderosa emissora e três temporadas de sucesso do programa. O valor pago às autoras a título de direitos autorais, entretanto, foi ínfimo, considerando os altos custos de uma produção televisiva.

Interessante notar a diferença do papel desempenhado pelas autoras no blog, onde são as produtoras do conteúdo e estão no topo da hierarquia simbólica daquele ambiente, como microcelebridades; e no programa de TV, em que, ao cederem os direitos de utilização do texto para livre adaptação, perderam a autonomia nos processos de instituição discursiva ao se deslocar da CMC para os MCM.

\section{b) $\mathrm{O}$ caso Tess}

Em meados de 2009, Tessália Serighelli ganhou enorme notoriedade na rede social Twitter por atrair em pouco tempo um número expressivo de seguidores/as. Mesmo que ela tenha sido acusada no seu âmbito de atuação por ter se valido das possibilidades informáticas do meio para alcançar tal feito ${ }^{7}$, isso não ofuscou o fato dela figurar nos rankings das mais seguidas do Brasil: uma microcelebridade instantânea. A notoriedade na Internet rapidamente chamou a atenção de revistas, jornais e, enfim, da televisão. Nos meses seguintes, Tess, como é conhecida, concedeu entrevista para a revista Playboy e posou para ensaio fotográfico na revista masculina Vip. Em seguida, foi convidada pelo diretor do BBB para participar da décima edição do reality show, sem passar pelo processo seletivo regular imposto aos/às demais concorrentes. ${ }^{8}$ Durante o curto período em que esteve na casa, sua participação foi conturbada. A disposição inequívoca para o jogo, o desentendimento com alguns/as concorrentes e o envolvimento amoroso com Michel, um participante que declarou ter namorada, lhe rendeu a antipatia do público. Vários veículos massivos estamparam imagens de Tessália, indicada como uma vilã histórica da longa carreira do programa. A Revista de fofocas televisivas Tititi n. 595 publicou, quando ela ainda estava no programa, uma chamada de capa intitulada "BBB10: ex-participantes explicam por que o público tem tanta bronca de Tessália". Na matéria propriamente dita, ela é apontada como uma das maiores "vilãs" de toda a história do programa, definida como "manipuladora e egoísta sem culpa". No Twitter, foi criado um tópico denominado “@foratessalia”, com milhares de adesões.

\footnotetext{
${ }^{7}$ Ela foi acusada de ter usado scripts, linha de comando computacional do Twitter que permite, ao seguir instantaneamente milhares de pessoas, angariar por reciprocidade milhares de "seguidores" no mundo todo, recurso considerado por muitos como anti-ético ou pouco fidedigno.

${ }^{8}$ Outro participante, o twiteiro "Mr. Orgastic" também foi convidado a participar sem seleção, em uma estratégia da emissora de ampliar a repercussão do programa, marcadamente popular, nos domínios da Internet.
} 
Indicada para um "paredão triplo" contra dois oponentes, Tessália recebeu uma votação histórica, tanto pelo número quanto pela concentração: $78 \%$ dos 32 milhões de votos pediam sua eliminação. Interessante notar que Tessália, durante as atividades no confinamento, não fazia questão de dissimular ou negar sua posição de jogadora, ou seja, alguém que quer vencer e que utiliza estratégias visando este fim. Esta postura parece diferenciada daquelas recorrentemente utilizadas por participantes das várias edições do programa, que costumam afirmar uma suposta sinceridade e espontaneidade.

No fala do apresentador Pedro Bial, em seguida à saída de Tessália, essa postura foi nomeada como "esnobismo". Vale a pena transcrever o trecho:

Tessália, eu tenho uma tese: você entrou no programa achando que esse programa é um lixo e que você foi meio esnobe. Eu acho que quando a gente entra em algo que é um lixo, a gente tem que meter a mão no lixo, porque lixo é reciclável. Confundiram o seu esnobismo com falsidade. Tem um monte de gente tacando pedra em você (Pedro Bial, apresentador do BBB. Rede Globo, 02/02/2010).

A entrevista com os/as eliminados/as é parte constituinte do programa, mas o jornal popular Extra do dia seguinte, pertencente às Organizações Globo, oferece outra leitura para a fala do apresentador. Seu discurso foi apresentado como uma espécie de favorecimento, mesmo que sua afirmação de que "confundiram o esnobismo com falsidade" seja inequivocamente crítica. Como no trecho abaixo:

Na eliminação de Tessália, Pedro Bial foi bastante cuidadoso com ela. Defendeu a participante e deu espaço para ela falar. Todo mundo percebeu que existe um carinho pela morena, ficou nítido na conversa entre eles logo depois que ela saiu da casa (Jornal Extra, 03/02/2010).

Além disso, houve um consenso por parte do público de que ela teria praticado sexo oral por baixo dos edredons com o rapaz comprometido, resultando em um forte juízo moral por parte da audiência sobre o suposto fato, impossível de se confirmar. Nessa lógica sexista de cruzada moral, não chega a causar surpresa que a figura de Michel tenha saído ilesa do episódio. A Rede Globo exibiu enquetes feitas nas ruas de grandes cidades, nas quais as pessoas selecionadas na edição a definiram como "falsa", "traíra", "sem moral", "vagaba" e "cínica". 
O jornal popular "Meia Hora", do Rio de Janeiro, não usou de meias palavras, noticiando a eliminação, a exemplo de vários outros, em sua manchete de capa, na qual aparecia uma foto de Tessália em close chupando um picolé:

CHUPA, TESSÁLIA! Sister sai do jogo no terceiro paredão. Agora, vai ser chamada para fazer filme pornô. [Legenda da foto de capa:] Tess saboreia o picolé que ganhou de Michel ontem. (Jornal Meia Hora, 03/02/2010).

Na matéria correspondente, ela é definida como "peguete de Michel", e em um box, intitulado "Convite para fazer pornô", foi apresentada uma entrevista com o diretor comercial de uma produtora de filmes pornográficos, que disse acreditar que ela aceitaria sua proposta. Posteriormente, em entrevista, Tessália afirmou que jamais faria um filme do gênero.

No Youtube, dezenas de vídeos mostram a suposta cena sob os cobertores, apresentados com comentários agressivos e/ou chulos como "Boquetess", "Falsalia", "Pistoleira", "vadiaaaaaaaaa" entre outros menos publicáveis. Mesmo que em número bem menos expressivo, comentários de defesa da participante também foram observados:

sab eu vejo esses comentarios de vcs e ai eu sei o porque de o brasil não ir pra frente...

quem assistiu o programa 24 horas sab que a tessalia não é esse monstro na minha opinião ela foi verdadeira demais o brasil gosta de gente que faz teatro é so ver quem foram os ganhadores dos outros (comentário ao vídeo de trecho do BBB10 no site Youtube).

De volta ao Twitter, as primeiras postagens de Tessália após a eliminação enquadram o tempo passado na casa do BBB como um período de exceção, em uma espécie de reencontro com seus/suas seguidores/as, e ainda reafirma o Twitter como o seu ambiente familiar. O mundo da televisão é sutilmente desqualificado, como algo estranho a ela, algo "de fora":

Perdi muita coisa nesse mês fora?

Acho que me dou melhor com pessoas virtuais mesmo

O desfecho da meteórica passagem de Tessália pelo universo televisivo é resultante da sua recusa em se adaptar às lógicas próprias desse meio. Entrar na televisão para "esnobá-la" foi uma espécie de crime sem perdão. As alternativas apresentadas a ela para prosseguir sua trajetória midiática - revistas ou filmes "masculinos" - reiteram o sentido humilhante de objetificação das mulheres já tantas vezes denunciado pelos estudos feministas. Como bem salientou Huizinga (1971) há mais de setenta anos, no mundo dos jogos (e da grande mídia) 
um/a trapaceiro/a é sempre mais bem aceito/a que o desmancha-prazeres: trapaceia mas não "estraga o jogo."

\section{Conclusão}

Os dois casos apresentados permitem algumas inferências com relação à participação de microcelebridades em meios de comunicação de massa. Primeiramente, o lugar simbólico de uma microcelebridade da CMC nos MCM não é facilmente distinguível do de outros anônimos, "figurantes" na cena midiática. Não há nenhuma concessão à "fama" previamente conquistada em meios digitais, a não ser o próprio convite a "ir para a tv." Já o contrário é verdadeiro: aparecer na mídia é um imenso capital simbólico para blogueiros/as, twiteiros/as etc. em suas redes.

Em segundo lugar, as lógicas dos meios massivos são implacáveis: os programas de televisão não mudam suas rotinas ou processos de produção por causa de uma microcelebridade, esta é que tem que se adaptar. No caso das blogueiras do Mothern, a opção foi clara: ou a autorização para adaptar os textos é ampla, total e irrestrita, e o valor proposto é aceito sem questionamento, ou o programa de tv não será produzido. Em troca, a veiculação midiática do nome do blog e de sua logomarca ajudaram a vender o livro (que foi relançado com uma tarja indicando "o livro que deu origem ao seriado do GNT") e a participar de dezenas de entrevistas em outros programas da mesma emissora, como parte da campanha de lançamento. Como as blogueiras aceitaram os termos propostos, obtiveram este pequeno lucro financeiro e simbólico, mas à custa de ceder todas as posições libertárias e vanguardistas defendidas no blog. Já Tessália aceitou o convite, mas não cedeu: sua fragorosa derrota no programa e as humilhantes opções de retorno/permanência na grande mídia (segundo os jornais do dia seguinte) evidenciam o preço a ser pago pelo desafio à hegemonia dos meios massivos.

Um último ponto a destacar é a necessidade de se relativizar o potencial transformador das consciências atribuído aos meios digitais. O suposto lugar de explicitação das diferenças, da livre manifestação do pensamento e da democratização das enunciações parece fraco diante da dependência da legitimação massiva conferida pelos MCM. O radical moralismo e conservadorismo vitorioso nos dois casos mostra que ainda há um longo caminho a percorrer antes de uma efetiva mudança social. 


\section{Referências bibliográficas}

BARNES, Susan. Computer-mediated communication: human-to-human communication across the Internet. Boston/USA: Allyn and Bacon, 2003.

BECKER, Howard S. "As Políticas da Apresentação: Goffman e as instituições totais" in: GASTALDO, Édison (org.). Erving Goffman, desbravador do cotidiano. Porto Alegre: Tomo Editorial, 2004.

BOURDIEU, Pierre. Sobre a Televisão. Rio de Janeiro: Record, 1998.

BRAGA, Adriana A. Personas Materno-Eletrônicas: feminilidade e interação no blog Mothern. Porto Alegre: Sulina, 2008.

. "Todo mundo pode ter blog? Práticas de legitimação na blogosfera". In:

RODRIGUES, C. (Org.). Jornalismo On-line: modos de fazer. Rio de Janeiro/Porto Alegre: Editora PUC-Rio/Sulina, 2009.

BRAGA, A.; GASTALDO, É. O Legado de Chicago e os estudos de recepção, usos e consumos midiáticos. Revista FAMECOS n. 39, p. 78-84, 2009.

BRITTOS, Valério C. “Televisão e barreira: as dimensões estética e regulamentar." In: Othon Jambeiro; César Bolaño; Valério Brittos (Orgs.). Comunicação, informação e cultura: dinâmicas globais e estruturas de poder. Salvador: Editora UFBA, 2004, v. 1, p. 15-42.

CHARAUDEAU, Patrick. Language et Discours: elements de sémioliguistique. Paris: Hachette, 1984.

DYER, Richard. Heavenly bodies: film stars and society. London: Routledge, 1986.

GOFFMAN, Erving. A Representação do Eu na Vida Cotidiana. Petrópolis: Vozes, 1998.

HOLMES, Su \& REDMOND, Sean. "A Journal on Celebrity Studies." In: The Celebrity Studies Journal (1/1). London, Routledge, 2010.

MAINGUENEAU, Dominique. Análise de Textos de Comunicação. Campinas: Pontes, 1998.

MARSHALL, P.David. (org.) The celebrity culture reader. New York/Oxford: Routledge, 2006.

SIMMEL, Georg. Sociologia. São Paulo: Ática, 1983.

THOMAS, William I. "The Definition of the Situation” in: The Unadjusted Girl. New York: Little, Brown \& Co, 1923.

WALTHER, Joseph B. "When is mediated communication not interpersonal?" In: GALVIN, K. \& COOPER, P. (Eds.) Making connections: Readings in relational communication. Los Angeles: Roxbury Publishing Company, 1996. 